\title{
Quantitative Determination of the Amount of Copper(I) Oxide in the Corrosion Products Formed on Copper by the Potassium Permanganate Titration Method
}

\author{
Kun $\mathrm{Li}^{1,2,3,4}$, Zhuoyuan Chen ${ }^{1, *}$, Xiaoying Sun ${ }^{1}$, Jian Hou ${ }^{4}$, Fengling $X u^{4}$, Likun Xu ${ }^{4}$ \\ ${ }^{1}$ Key Laboratory of Marine Environmental Corrosion and Bio-fouling, Institute of Oceanology, \\ Chinese Academy of Sciences, 7 Nanhai Road, Qingdao 266071, China. \\ ${ }^{2}$ University of Chinese Academy of Sciences, 19 (Jia) Yuquan Road, Beijing 100039, China. \\ ${ }^{3}$ Luzhong Secondary Specialized School, 22 Huangshan East Road, Zouping 256200, China. \\ ${ }^{4}$ State Key Laboratory for Marine Corrosion and Protection, Luoyang Ship Material Research \\ Institute, 149-1 Zhuzhou8 Road, Qingdao 266101, China. \\ *E-mail: zychen@qdio.ac.cn
}

doi: $10.20964 / 2017.12 .23$

Received: 20 August 2017 / Accepted: 15 October 2017 / Published: 12 November 2017

In the present work, an improved titration method, called the potassium permanganate titration, was developed to quantitatively measure the mass of copper(I) oxide in the corrosion products formed on copper. This method can accurately measure the mass of copper(I) oxide on the copper surface, and the error is within $\pm 3 \%$, which was calibrated by microgravimetry. The accuracy of this improved method is higher than other current commonly used methods for determining the amount of copper(I) oxide. The effect of oxygen on the accuracy of the measurements was studied, which determined whether the operating environment of each step was in an aerobic or anaerobic environment. It was verified that ammonia can act as the solvent to completely dissolve the corrosion products without damaging the copper matrix. The amount of the copper(I) oxide formed on copper surface was also measured using this method. The potassium permanganate titration is particularly applicable to determine the amount of copper(I) oxide on the copper exposed in atmospheric environments in the absence of chloride ions.

Keywords: copper(I) oxide, potassium permanganate titration, quantitative determination, copper, atmospheric corrosion products

\section{$\underline{\text { FULL TEXT }}$}

(C) 2017 The Authors. Published by ESG (www.electrochemsci.org). This article is an open access article distributed under the terms and conditions of the Creative Commons Attribution license (http://creativecommons.org/licenses/by/4.0/). 